\title{
'I feel like I have to become part of that identity': Negotiating femininities and friendships through alcohol consumption in
}

Newcastle, UK

Emily Nicholls, University of Portsmouth

Whilst women's excessive alcohol consumption has traditionally been regarded as a potential threat to health, safety and even femininity, recent research highlights the important role that alcohol plays in many young women's lives. Drawing on data from semi-structured interviews with women aged 18-25 in Newcastle, UK, this paper will consider the role that alcohol can play in the negotiation of female friendships in the Night Time Economy, highlighting the ways in which young women may regard alcohol as a tool to enhance socialising, trust and intimacy (both when pre-drinking and in bars, pubs and clubs). The role of alcohol in 'doing' gender and femininity will also be explored, as young women collectively display feminine identities through particular drinking choices and practices that may include heavy drinking and drunkenness. Finally, I will consider the implications for young women who do not engage in these collective practices of alcohol consumption and suggest avenues for future work on the under-researched topic of the experiences of non-drinkers.

Keywords: alcohol, gender, femininity, friendship, Night Time Economy, non-drinkers 


\section{Introduction}

Women's excessive alcohol consumption and visible intoxication within the United Kingdom has long been depicted as a threat to their health, safety and - perhaps most interestingly - their femininity (Day et al. 2004). However, the landscape of the UK's Night Time Economy (NTE) has changed considerably in the past few decades, leading to claims that late-night leisure spaces such as bars and clubs are becoming increasingly 'feminised' (Fileborn 2016) and women's drinking and drunkenness is now normalised and expected. The collapse of heavy industry and decline of the 'working man's' community pub and attempts by the alcohol industry to target women as a lucrative consumer market have provided increasing opportunities for women to drink more freely in public space. Research suggests that alcohol consumption amongst young women in the UK increased during the early part of the $21^{\text {st }}$ century (Bailey et al. 2015), with drinking and participating in the NTE recognised as important elements of the lives of many young women (Chatterton and Hollands 2003; Waitt et al. 2011).

Recent research explores the ways in which a 'night on the town' is likely to offer opportunities for young women to socialise with friends and relax (Guise and Gill 2007; Jayne et al. 2010; MacLean 2016). There is also an emerging body of literature focusing specifically on the 'girls' night out' with female friends, which again draws our attention to the central role that frequenting bars, clubs and pubs may play in young women's lives (Waitt and Clement 2016; Nicholls 2019). Drinking - on the 'girls' night out' and in the NTE more widely - has been framed to some extent as an opportunity for women to redefine feminine subjectivities, rewrite sexual and gendered scripts and challenge gendered power relations (Peralta 2008; Hartley et al. 2014; Kovac and Trussell 2015; Waitt and Clement 2016). However, there is a need for further research to explore in more depth the ways in which drinking (and drunkenness) may also be used as a means to achieve - rather than resist feminine identities, and to highlight the implications of this for young women who do not drink.

This paper will highlight the ways in which alcohol can be understood as a tool - albeit at times an unpredictable and unwieldy one - to enable young women to 'do' femininities and friendships in the NTE. I will explore the ways in which alcohol is used to enhance socialising and to establish trust and intimacy in ways that 'cement' friendships, before considering how choosing certain drinks and 
consuming them with female friends can also function as a means to 'do' femininity collectively. Finally, I will consider the implications of these findings for young women who do not drink, drink too little or even who drink the 'wrong' type of alcohol. If drinking plays such an integral role in negotiating both friendships and femininity in a night out context, what might the consequences be for those who do not participate in the 'right' ways? Whilst the experiences and views of young people who drink particularly students - are well-represented in existing research, there is only a small body of work exploring the experiences of non-drinkers (see for example Nairn et al. 2006; Herman-Kinney and Kinney 2013; Conroy and de Visser 2014; Herring et al. 2014). Further research in this area is important as research suggests young people's alcohol consumption across Europe has plateaued and even begun to decline (Pape et al. 2018; Oldham et al. 2018). I will conclude this paper by suggesting that this is a fruitful area for further study.

\section{Background to the project}

The findings presented in this paper stem from a 3 year project funded by the Economic and Social Research Council and based in Newcastle-upon-Tyne, UK. The 'Girls' Night Out Project' explores young women's understandings of what it means to be appropriately 'feminine', and ways in which the shifting boundaries of femininity are negotiated within contemporary nightlife contexts. The project took as a starting point the notion that gender is socially constructed and performative. In other words, the notion of a fixed gender identity is merely an illusion as we must continually repeat the practices and behaviours recognised as 'masculine' or 'feminine' to produce bodies and identities that are read as 'male' or 'female' (Butler 2004). Indeed, it is this repetition of practices that brings so-called gendered bodies into existence in the first place, meaning gender is not innate or natural but rather a mundane accomplishment achieved through the embodiment of 'masculine' or 'feminine' traits and behaviours (West and Zimmerman 1987), which may include particular gendered drinking practices. For women, to 'do' gender is to 'do' femininity successfully, meaning it is important to consider the traits, dispositions and behaviours that are seen to comprise 'appropriate' femininity, and the ways in which these may have changed over time. Whilst femininity is a slippery, shifting and fluid concept that can remain difficult to pin down (Holland 2004), Curtin et al. suggest that 'femininity ideologies can be defined as ideas, norms, and restrictions about what constitutes "normal," acceptable, and ideal womanhood', and these ideologies traditionally emphasise traits such as 'passivity, compliance, concern for others, and agreeableness' (2011: 49). Historically, the feminine body is characterised by 
fragility, lack of agency and a degree of self-discipline and self-control (Holland et al. 2004), and is expected to embody 'respectability' in the form of control over the body, sexual behaviour and desire (Skeggs 1997).

The Girls' Night Out Project sought to explore some of the nuances around negotiating femininities today - particularly through practices of alcohol consumption - and to ask whether women even consider being 'feminine' to be an important part of their lives. My intention was to explore and understand some of the ways in which ideologies of femininity and girlhood are interpreted, adopted and embodied in women's everyday lives (Herridge et al. 2003) as they consume alcohol, get drunk and participate in the NTE. The NTE's status as 'an important public leisure space' where 'gender is embedded and created' (Kovac and Trussell 2015: 197) means it is an important and relevant contemporary site through which to explore ways in which gendered identities are negotiated.

Over the course of 2012 and 2013, I conducted and thematically analysed 26 in-depth interviews with women aged 18-25 in Newcastle, exploring the ways in which young women frame the boundaries of appropriate femininity, and the ways in which 'appropriately' feminine identities are negotiated and displayed through alcohol consumption on the girls' night out. Interviews were semi-structured in order to facilitate in-depth discussions, to allow participants to direct the conversation to an extent and to allow the researcher to follow-up points of interest through the use of prompts and probes. The research process also drew on elements of storytelling or narrative interviewing through asking participants to tell a chronological 'story' of a 'typical' night out with female friends as the starting point of the interview (McCormack 2004). This focus on the ways in which participants 'tell' their experiences provided rich data in the form of 'cultural stories' regarding their practices, behaviours and identities on a night out and what these meant to them (Haydock 2009). The elements of narrative interview also allowed me to identify striking commonalities across the different interviews in their 'stories' of what a girls' night out entails; it necessarily includes only female participants, usually an existing friendship group, who 'pre-drink' and get ready at one of the young women's houses. The night then involves further collective drinking in bars and in a 'mainstream' club in the city centre (and it can be seen as an overtly heterosexualised form of participation in the NTE). The girls' night out represents a discreet and distinctive mode of engagement with the NTE, yet one that has received 
little attention in research, despite the fact that it is likely to reveal a huge amount about the individual and collective production and negotiation of femininities and friendships in nightlife venues.

All interviews were fully transcribed, and data was coded into themes manually in order to keep the researcher 'close' to the material. Thematic analysis was adopted as this is a useful way to explore patterns and commonalities across what might initially seem to be a varied and broad dataset (Braun and Clarke 2006). This approach allowed me to explore and highlight the ways in which the participants make 'meanings' around their participation in the NTE, and facilitated the use of both an inductive and deductive form of analysis. Deductively, I came to the data with a rough list of preexisting potential themes, but this approach also provided flexibility for new themes to emerge more inductively from the data. As Joffe (2012) suggests, this ability to be 'led' and guided by the data itself is important, and in practice this allowed for some themes that were not anticipated in advance (such as the importance of age) to be identified and explored. Themes were first identified within interviews and then across interviews; sub-themes and links between themes were also mapped out. All coding and analysis was carried out by the author. It is important to acknowledge that qualitative researchers potentially retain a great deal of power in terms of how they code, understand, interpret and disseminate the words of participants (Maynard 1994; Letherby 2002). With this in mind, I attempted at all times to remain truthful to what I felt the participants were saying, through seeking clarification in the interview where required, and attempting to interpret quotes within their original context rather than artificially 'chopping' data into themes and losing a sense of wider context.

In an attempt to secure a relatively diverse sample of young women, participants were recruited through both Russell Group ('elite', research-intensive) universities and 'new' (former polytechnic) universities, alongside a range of workplaces and a local college. Recruitment in college and university sites involved distributing flyers, sending emails to university societies and attending a large range of classes to meet students and invite them to contact me if they were interested in the research. Recruitment within workplaces was facilitated less formally through word of mouth and snowballing, and a number of participants were also recruited through a dedicated Facebook page 'shared' initially by friends and then beyond my existing friendship group. Participants identified with a range of sexualities (two-thirds heterosexual, one-third bisexual, lesbian or queer) and class backgrounds ( $46 \%$ working-class, $31 \%$ middle-class and $23 \%$ 'do not identify with a class'). All 
participants were White British, and whilst I have explored elsewhere the salience of race, class and regional identities in this research (Nicholls 2019), such analysis is beyond the scope of this paper. It is also interesting to note that regardless of class identity, there were several overlaps and similarities in the ways in which alcohol consumption and drinking practices were discussed. Likewise, I have explored in more depth some of the ways in which sexuality and sexual orientation shape experiences of the NTE elsewhere (Nicholls 2017).

\section{'Friendship-cementing'; Socialising, trust and intimacy}

Almost all of the participants described the girls' night out as offering important opportunities to socialise and spend time with female friends, with some even framing it as the main or only way they socialised. For example, Nicole uttered in confessional tones that nights out with female friends are 'the centre of my world'. Others described nights out as 'time to chat, socialise and catch up' (Alex) and 'integral' to maintaining friendships (Jessie). Alcohol was framed as absolutely central to a girls' night out; drinking (usually to the point of getting at least mildly to moderately 'drunk') was normalised and expected in these contexts and tied to being 'fun' and sociable. Several participants of a range of sexual orientations also suggested that consuming alcohol helped to establish a form of dedicated 'girl time', with the opening and sharing of a bottle of wine - for example - marking the transition to this important form of leisure and creating private time and space to socialise (see also Barton and Husk 2014):

If I go out with only female friends, we make a bit more of a, kind of, thing of drinking together beforehand, and chatting and that.... [cut].... as in like 'here's a bottle of wine, now let's sit and chat about our lives'.

Gail, 24

'Pre-drinking' often took on a particularly important role on a girls' night out, as Gail suggests, where it allowed a carving out of space for young women to 'sit and chat about our lives'. In contrast to the loud and chaotic public space of the NTE, pre-drinking in domestic spaces could provide women with dedicated 'time to ourselves' and feel like 'a little private party' (Jade). Gail's emphasis here on drinking 'together' also reminds us that solo alcohol consumption - particularly alone at home - may 
still be framed as problematic for women (Niland et al. 2013). Rather, the shared and collective nature of drinking here allows women to justify alcohol consumption as a social pleasure. Alcohol consumption could also enhance feelings of connection and intimacy and 'drinking time' could become a time and space for candid, open and uninterrupted conversations (Jayne et al. 2011). Drinking together was linked for several participants with establishing closeness and getting to know other women better; functioning as a 'friendship-making' practice (MacLean 2016). Arguably, such outcomes could be more easily facilitated when participants drink enough to experience some of the effects of alcohol consumption, such as lowered inhibitions. Whilst lowered inhibitions could be seen to have both positive and negative consequences, a potential positive consequence was the facilitation of more open, emotional and honest conversations with other women. Once again, predrinking was particularly important here, helping to establish more relaxed and intimate spaces for socialising (Waitt and De Jong 2014). Women are also arguably able to maintain greater control over pre-drinking spaces (for example through control over lighting, music, drinking activities and access to alcohol). As Wilkinson (2017) suggests, control over factors such as lighting can be used to establish intimacy, and domestic spaces may represent a safe space in which to drink and relax outside of a NTE that is often characterised for women by concerns with both risk and visibility (Bancroft et al. 2014). These findings around the role of pre-drinking in establishing intimacy, closeness and openness amongst female friends are important, particularly as domestic drinking continues to be under-researched despite the key role consuming alcohol at home may play in the lives of people of all ages (Jayne et al. 2011).

Whilst alcohol consumption in the home tended to be associated with providing opportunities to catch up and socialise, the role of alcohol shifted later in the night. In a NTE characterised by loud music, limited seating opportunities and the potentially disruptive presence of other revellers, it is unsurprising that chances to socialise and initiate intimate conversations might be more limited. Rather, as the night spilled out beyond domestic space and into bars and clubs and consumption levels continued to increase, the emphasis shifted to focus on the ways in which caring for one another acted as another way to build friendships and trust. For example, Ally described a girls' night out as a setting where female friends have always 'got your back', a sentiment echoed by other participants: 
You get to see people at their worst when they're drunk [laughter], and so it makes everything else that little bit easier. If you can say to someone 'oh, by the way, I dragged you home crying for an hour last night' then there's not a lot they can do to shock you again. It's good fun. Not quite friendship-building, but friendship-cementing.

Donna, 21

For Donna, looking out for the wellbeing of female friends who are visibly drunk, upset or unable to get themselves home safely 'gives you an extra layer of relationship with them' and is 'friendshipcementing'. Ally also suggested a girls' night out provided you with 'someone to hold your hair back' if you were being sick, a particularly intimate physical gesture. For several of the participants, the messy, embodied consequences of intoxication - 'crying for an hour', losing the ability to get home safely or even vomiting in public - were not framed as problematic, but rather as further opportunities for bonding and intimacy (see also Griffin et al. 2009a). This is also apparent in other recent research exploring young people's alcohol use and friendship, most notably in the work of MacLean, who argues that 'getting very drunk so as to require care from friends is part of the point of going out, rather than an unintended consequence of it' (2016: 98). Of course, such actions and gestures could also be framed as further ways to 'do' femininity through nurturing and caring for others (Curtin et al. 2011). It is interesting to note that in these case, drunkenness was framed as somewhat normalised and expected and potentially resulting in positive effects on friendships, challenging to an extent the findings of previous research (Day et al. 2004).

It is clear that drinking was closely bound up with friendship in a number of ways for the participants, and these practices generally crossed boundaries of both class and sexuality. For several of the young women, drinking could also function more explicitly as a way to 'do' femininity or girliness together, as the next section will show.

'I've made myself like wine': Collective femininities and drink choices 
As suggested earlier in this paper, excessive drinking and the embodied effects of intoxication have been framed historically as a threat to women's femininity (Day et al. 2004). If drinking and drunkenness are associated with being loud, 'rowdy' or losing control of the body, this clearly violates expectations that the 'appropriately' feminine woman is quiet, passive and retains control over her body and behaviour (Holland et al. 2004). Indeed, by the early 1990s, alcohol consumption was being theorised as a type of embodied resistance against normative values around sexuality and gender (Papagaroufali 1992). More recent research has suggested that drinking can provide opportunities for young women 'to suspend, interrupt and dispense with aspects of their feminine subjectivities' (Brown 2014: 204), and to redefine or challenge existing gendered and sexual scripts (Peralta 2008; Hartley et al. 2014; Waitt and Clement 2016). The NTE may in some senses represent a 'liminal' space characterised by both pleasure and uncertainty (Hayward and Hobbs 2007), where normative expectations about gender and femininity may be disrupted or ignored. There were certainly some examples within the data of participants consciously doing so. For example, Fran suggested that she deliberately enjoyed drinking pints of beer despite - or perhaps in part because of? - her exboyfriend's continued attempts to steer her away from this 'unladylike' beverage choice. However, it is important to note that drinking does not necessarily disrupt feminine subjectivities, and examples of participants consciously flouting gendered expectations around drinking practices were relatively rare. Rather, alcohol consumption may allow female drinkers 'to accomplish a range of both traditional and non-traditional femininities' (Measham 2002: 362); many of the drinking practices and choices discussed in interviews helped the young women to portray - rather than resist - what they called a 'girly' identity. In this way, the traditionally masculine pastime of drinking could be recast as an activity which - in at least some contexts - could be positively associated for young female drinkers with femininity.

Perhaps the most obvious example of the ways in which drinking and femininity could intersect was through the gendering of certain drinks. To return to the example of Fran, we could argue that her insistence on drinking pints of beer was doubly deviant. Beer was commonly recognised as a more masculine drink, building on the historic associations between beer and masculinity (Lyons and Willott 2008; Rolfe et al. 2009), and it may also be seen as particularly problematic in pint form, with Fran suggesting that women are expected to drink from more 'petite' and delicate glasses. Whilst several participants continued to associate beer with masculinity, some also drew on classed connotations - 
as evidenced in previous work by Emslie et al. (2015) - to frame beer as simultaneously 'manly' and 'rough':

Women who drink pints is [sic] a bit manly, therefore a bit rough. If you were well-to-do and middle-class then you just wouldn't do it.

Nicole, 24

In contrast, supposedly more 'feminine' or girly drinks such as cocktails and wine were also felt to be - in the participants' own words - more 'classy', 'upmarket' and 'less uncouth' than beer and cider, as suggested in previous research where traditionally feminine beverages are labelled 'glamorous and sparkling' (Lyons and Willott 2008: 701). For example, Megan - a self-professed 'girly girl' - explained how 'she likes the way it looks' (as much as the taste) when she is holding an 'elegant' glass of wine. Joanna described how she'd love to be seen with a cocktail in 'a fancy glass' (although she often couldn't afford to drink them). Once again the emphasis was more on how the drink looks and feels than the taste per se. In this sense, 'the very vessels for alcoholic beverages have become an integral part of the experience for consumers' (Smith 2014: 62) and one's choices around alcohol 'may have implications for the achievement of a gender-specific identity' (Atkinson et al. 2012: 366). Perhaps this inextricable tangling of girly and classy is unsurprising, as women attempt to convey an image of respectable - i.e. middle-class - femininity whilst engaging in a practice (alcohol consumption) that has traditionally been framed as masculine. In one of the few differences along classed lines that was evident in relation to women's drinking practices, the working-class young women were particularly likely to draw on notions of certain drinks as classy, elegant or rough and to carefully associate themselves with more 'classy' and feminine drink choices. It is likely that working-class women have to work harder to draw explicit links between drinking and respectability. Indeed, as Skeggs argues, femininity is bound up with class and respectability, making it more difficult for working-class women to embody 'respectable' or 'appropriate' forms of femininity. In a night out context, as Griffin et al. argue, it is also much easier for middle-class young women to temporarily transgress the norms of femininity through alcohol consumption 'without falling into the position of the feckless drunken 
working-class slag' (2009b: 466). Here, femininity remains bound up with notions of respectability that continue to be shaped by notions of control over one's sexual behaviour and reputation.

It is important to note that these categorisations of drinks had real impacts on women's drinking practices and choices. A particularly interesting example of this comes when participants who would prefer to drink cider or beer felt the need to change their drinking choices and drink more 'feminine' beverages when out with their female friends. For example, Eve suggested that although she enjoys drinking cider and beer, she feels a need to drink 'really girly drinks like rose wine and cocktails' on a girls' night out. Likewise, Ally felt she had been required to train herself to drink wine - which she saw as more 'upmarket' than cider - with female friends. For both Ally and Eve, aligning drinking practices and choices with those of other women may become a means through which to collectively 'do' femininity. Ally admitted that 'I've made myself like wine', which suggests she had to work hard to almost force herself to drink something that she would rather not consume. In this way certain drinks may function as 'props' in social contexts and become 'consumption-driven signals of identity' (Smith 2014: 61) in nightlife spaces. Refusal to engage in collective drinking practices with friends could come with consequences and be read as a way to 'snub' female friends:

I feel like I kind of have to become part of that identity. And l'd feel like I was almost pushing them away a bit if they asked if I'd like to share a bottle of wine with them and I was just like 'oh no, l'll go and get a lager'. It's kind of like, when you're all there together, obviously you're an individual, but you're part of a group as well. And you feel inclined to do the same things, and drink the same kind of things.

Eve, 24

Here, the collective drinking practices expected on a girl's night out are important, and failure to buy into collective processes of identity construction could be experienced by young women as a way of rejecting female friends or 'pushing them away' (see also Bartram et al. 2017). Eve draws on her dual positioning as an individual but also as 'part of a group' and considers the implications this might have for collectively portraying more feminine identities through certain drink choices. Interestingly, both Ally and Eve identified as bisexual, and it may be that they experienced particular forms of imagined or real pressure to 'fit in' when engaging in the explicitly heteronormative context of a 'girls' night out' 
in mainstream bars and clubs (particularly as it might be normalised or even expected that lesbian or bisexual women would drink beer on the gay scene (see Emslie et al. 2017)). In contrast, participants such as Nicole, Megan and Joanna - who most enthusiastically talked about drinking 'girly' drinks and enjoying the way these drinks look and taste - all identified as heterosexual.

Overall, it is clear that alcohol could - to an extent at least - be used as a 'tool' to facilitate the 'doing' of both femininity and friendship, echoing previous anthropological research describing alcohol as a social tool or 'social artefact' (Dietler 2006: 230). Having said this, the term 'tool' implies something of a reliable, predictable object that can be subverted to the user's ends easily, but alcohol can be unwieldy and unpredictable and can 'act back' on the body of the user (for example through the embodied effects of drunkenness). Whilst there was some recognition of this amongst the participants (particularly in acknowledging that 'overshooting' consumption levels and losing control of the body can actually hinder one's ability to do femininity), most of the young women positioned themselves as capable drinkers who 'knew their limits' and were able to control, manage and monitor the ways that they used alcohol in social settings. This of course continues to be bound up with notions of 'appropriate' femininity associated with self-control and self-discipline (Holland et al. 2004). Yet this had to be balanced with the pleasures of 'getting drunk' as a means to enhance intimacy and provide opportunities to care for and support others. It is little wonder that the participants themselves were aware of some of these tensions around managing one's level of intoxication.

Alcohol clearly plays a central role in the NTE, and it was clear that a girls' night out in particular could place specific demands on young women around alcohol consumption. If this is the case, what might the implications be for young women who resist expectations to drink in particular ways, or drink no alcohol at all? With youth drinking in decline over the last 10-15 years according to recent research (Oldham et al. 2018), this is an important area for further investigation.

\section{'You're not honouring a part of the agreement': Resisting expectations to drink}

As Herring et al. (2014) argue, there is currently only limited research with young people who abstain from drinking alcohol, and whilst all of the women in this sample were current drinkers, some (of a range of class backgrounds and sexual orientations) did talk about times they had tried to abstain or 
moderate on a night out, explaining that this was met with resistance. For example, Georgina had not drunk on a night out for the last 10 months in order to save money for a new car, and Claire had recently started drinking again after a period of 3 months of abstaining for health reasons. Georgina and Claire were notable exceptions; for most of the young women, the thought of going out sober was extremely unappealing. Some participants had simply never done it, some described it as 'boring' or 'pointless' and others would rather stay at home than go out sober.

Consumption patterns in leisure spaces have become an important way to embody and live out gendered identities (Atkinson et al. 2012), and it is likely that young people experience pressure to consume in certain ways and display particular types of identity (Winlow and Hall 2009), suggesting there may be consequences for young women who do not engage in collective drinking practices. All participants certainly recognised that alcohol plays a pervasive role in the NTE and situated themselves within a culture of normalised heavy or binge drinking (Griffin et al. 2009b). Women's positioning of alcohol consumption as an 'essential' part of a night out may also represent what Leve et al. (2011) describe as a 'normalisation' strategy, whereby potentially risky behaviour such as drinking can be justified through positioning it is as 'normal' and 'ordinary'. As Jessie suggested, getting 'a bit drunk' with female friends can feel like a compulsory part of the girls' night out, a form of unspoken agreement that needs to be 'honoured' because it is associated with 'fun':

I'd not say 'oh I'm not drinkin' tonight' or 'I'm only gonna have, like, two drinks tonight'. I'd never vocalise that, because then it's like you're not honouring a part of the agreement in going out, which is to get a bit drunk, because then you will be fun.

Jessie, 21

Against a backdrop of neoliberalism, 'the active consumer of alcohol is seen as a good citizen' (Haydock 2009: 85) (although within certain limits of course). As a result, young people may feel compelled to express themselves through drinking. Jessie even admitted that 'I don't think that I particularly like it [drinking], and I'm not sure that a lot of people really like it', and attributed heavy drinking to peer pressure and expectations rather than it necessarily being an inherently pleasurable experience. Peer pressure was certainly a recurrent theme in the data, and friends who did not drink alcohol were at times viewed as annoying, weird, stuck-up or boring: 
If one person's staying sober it's really awkward.

Emma, 20

If people around you aren't enjoying themselves, then that's obviously a massive downer. Like, one of my housemates has a bad habit of, on nights out, she goes 'I'm gonna look after everyone'. Which means she doesn't drink, which means she ends up in a club, bored out of her mind. And you're just dancing round her, completely drunk, going 'drink! Drink, woman!'

Donna, 21

Emma and Donna both frame non-drinkers (even those who decide to abstain occasionally or sporadically) as changing the atmosphere of a night out. Donna describes her housemate's occasional choice to abstain as a 'bad habit', an interesting choice of phrase as - far from being a 'bad habit' - we could argue that the decision to abstain may come with potential positive health or cost implications that are certainly not acknowledged here. It is also interesting to note that her housemate's reasons for staying sober (to 'look after everyone') are rejected or go unappreciated. As discussed previously, looking after other women when consuming alcohol was frequently seen as a way to develop trust and intimacy between friends, but perhaps only when all the young women involved had been drinking heavily. A final point to note is Donna's acknowledgement that peer pressure - 'drink! Drink, woman!' - is applied to those who are not consuming alcohol on a night out.

Non-drinkers may recognise the ways in which abstaining positions them as something of a 'black sheep' (Conroy and de Visser 2014) and, as Jessie suggests above, may keep quiet about attempts to abstain, or even to cut down, moderate or limit alcohol consumption in order to avoid intense questioning about this choice or peer pressure to consume alcohol. Even attempts to moderate and have 'like, two drinks' would be best kept hidden or secret, suggesting that women who do wish to drink less - or not at all - may experience difficulties in terms of being open about their intentions and may try to conceal non-drinking or to 'pass' as drinkers (see Nairn et al. 2006). This further affirms the idea that drinking per se is not what matters, but drinking to a certain level in order to be 'tipsy' or a 'bit drunk'. It is unsurprising that non-drinkers are likely to adopt a number of strategies to avoid being labelled as deviant (Bartram et al. 2017), including concealing non-drinking status (Romo et al. 2016) and fictional 'story telling' about why they are not drinking (Herman-Kinney and Kinney 2013). Hayley 
- one of the few participants who did consume alcohol but who did not frame it as a required 'tool' to negotiate a night out - described a decision to abstain as something that might be challenged or lead to probing questions or interrogations:

I can go out and I don't need to have a drink, but sometimes if I'm out with a different group of friends, they will challenge that... 'What you not drinking for? Are you ill?' and stuff like that.

Hayley, 24

As Conroy and de Visser (2013) suggest, non-drinking is often framed by drinkers as something requiring explanation which could threaten one's ability to 'fit in'. In addition to probing questions, Georgina described some of the tactics her friends might use to encourage her to drink, including trying to make her feel guilty ('oh you've not been out with us for ages') and trying to undermine or challenge her stated reasons for abstaining (as they knew Georgina was trying to save money, strategies might include stressing that alcohol is 'not that expensive'). It is also noteworthy that both Georgina and Claire (who had been sober for three months prior to participation in the research but was now drinking again) provided specific and concrete justifications for their non-drinking. Georgina's emphasis on saving for a car suggests her non-drinking was a practical, cost-saving measure with presumably - a specific end date in sight. Non-drinkers may actively reject or refuse a collective nondrinker identity (Banister et al. 2015), and Georgina positions herself as someone who is temporarily not drinking for a specific purpose, rather than as a non-drinker per se. Claire attributed her brief period of non-drinking and subsequent decision to drink less to a new relationship with a partner who doesn't drink, and perhaps more prominently to health concerns:

I had my DNA sequenced, I had my genome sequenced. And it turned out that my genes mean I'm much more likely to have cirrhosis of the liver, so drinking heavily is more dangerous for me than it is for most other people. I went about 3 months without drinking at all. Now I don't not drink, but I don't drink heavily anymore.

Claire, 25

This defence allows Claire to offer up what Conroy and de Visser's (2014) might term a 'culturally sanctioned' reason for abstaining (significant health issues) rather than a 'culturally unsanctioned' one (such as merely wanting to drink less or not at all). Linked to this, with alcohol a recognised tool for 
achieving specific modes of collective femininity, Hayley's reasoning that she simply doesn't need to have a drink is unsanctioned and met with demands to provide some form of satisfactory explanation for not drinking (such as being unwell and on antibiotics). The questioning of whether Hayley is 'ill' also of course implies that there must be something 'wrong' with her that explains her decision not to drink. Claire is also able to abstain or moderate without critiquing the practices of other drinkers, by positioning herself as someone who is particularly 'at risk' when it comes to drinking ('drinking heavily is more dangerous for me than it is for most other people'). As Bartram et al. suggest, non-drinkers may 'take care to present their drink refusal in ways that do not appear to judge others for drinking' (2017: 454). Here, the fact that heavy drinking poses both short and long-term health risks to all drinkers is ignored or downplayed, allowing Claire to argue that for genetic reasons she should personally limit her own consumption, but without suggesting she might be judging the widespread and normalised drinking culture.

The consequences for non-drinkers can be very real and include exclusion, social isolation or even verbal abuse and physical harassment (Herman-Kinney and Kinney 2013; Romo et al. 2016). Whilst previous research suggests non-drinking could actually earn respect and be linked to sociability, it could simultaneously be read as a rejection of one's friendship group and positioned as unsociable (Conroy and de Visser 2013). To be present but sober in nightlife contexts is thus to risk feeling excluded or ostracised; 'to be without alcohol is to feel alone among friends' (Niland et al. 2013: 534). Non-drinkers could even risk exclusion from their own friendship groups (Advocat and Lindsay 2015), as Nicole implied:

I've got a friend who doesn't drink as well - she doesn't really come out with wur [us] anymore, I wonder why(!)

Nicole, 24

Overall, it is clear that challenges exist for those who abstain - or perhaps even try to limit or reduce their consumption - for culturally unsanctioned reasons (Conroy and de Visser 2014; Bartram et al. 2017). There was no mention in the data of young women receiving any support or encouragement if they made attempts to abstain from drinking on a night out, or even to moderate. Rather, abstaining from alcohol consumption might be experienced as a very real 'source of social exclusion' (Griffin et 
al. 2013: 188; see also Järvinen and Gundelach 2007). It is also interesting to note that there was little differentiation across the findings on this issue in terms of class and sexuality, suggesting that the imperative to consume alcohol cross-cuts or overrides these differences. As previous research has identified, there may be real benefits to undertaking further research in this field (Conroy and de Visser 2015). Current health campaigns tend to promote the benefits of 'moderation' in terms of alcohol consumption, but evidence suggests current guidelines and recommendations are not necessarily adhered to (Furtwængler and de Visser 2013), with up to $20 \%$ of the UK population drinking above the recommended weekly guidelines in 2016 (Drinkaware n.d.). There was certainly no discussion in my own research of government guidelines or counting units. Rather, further research into the strategies used to manage non-drinking (including both practical strategies and how any stigma associated with abstinence is managed) may provide useful lessons around how to encourage drinkers to abstain in some social contexts (Herring et al. 2014; Conroy and de Visser 2015) or diversify their leisure practices to include alcohol free activities (Bartram et al. 2017).

\section{Conclusion}

This paper has begun to explore some of the discrete and specific functions of alcohol on the girls' night out, and the ways in which non-drinking might be policed or judged in these contexts. The data presented here clearly extends earlier research suggesting that alcohol consumption plays an important role in female socialising and the negotiation of both friendships and femininities (see for example Sheehan and Ridge 2001; Guise and Gill 2007; Jayne et al. 2010) in contemporary leisure contexts. Alcohol consumption is clearly a culturally significant marker of collective belonging in nightlife venues (Fileborn 2016: 171) and can also give young women a feeling of 'togetherness' and connection (Jayne et al. 2010). Alcohol and drunkenness were certainly felt to play a key role in facilitating and consolidating female friendships; it is clear that the girls' night out was felt not only to represent an important way to spend time with female friends, but also an opportunity to bond and socialise through collective alcohol consumption. An emphasis on friendship and on drinking to the point of intoxication as something sociable also allows women to position their consumption as not just 'normal and 'ordinary' but even 'expected' or 'essential'. Particular drinking practices - such as collectively consuming more 'feminine' drinks like wine or cocktails - could also be portrayed as ways to 'do' femininity within the female friendship group, highlighting the ways in which certain drink choices can be deployed in the 'accomplishment of feminine ideals more generally' (Atkinson et al. 
2012: 378). Consuming certain types of alcohol could clearly enable 'girliness' to be embodied in particular ways through certain consumption choices; indeed, alcohol consumption may be a way to embody a particular classed type of gendered respectability (Atkinson et al. 2012), particularly for working-class women who may lack access to other routes to 'respectable' femininity (Skeggs 1997).

Overall, it is clear that consuming alcohol may provide various, valued opportunities for co-producing femininities and bolstering friendships on the girls' night out. Indeed, the two may overlap, as many of the participants associated being 'feminine' or 'girly' with a sense of 'togetherness' and closeness to female friends (drawing on phrases such as 'girly giggles' and 'girl time'). This reflects Green's (1998) argument that doing female friendship in leisure spaces is a key component of the negotiation of gendered identities, and suggests that engagement with the NTE may be a key means through which women can do both femininities and friendships, with some overlaps between the two. However, the two might also to some extent be at odds as drunkenness could be felt to enhance friendships and create intimacy, yet women also recognised the importance of staying in control of their drinking to achieve a suitably 'feminine' identity. Vomiting is a case in point; something that could contribute to a feeling of intimacy and bonding with friends offering care and support, yet might undermine one's ability to embody a controlled, 'classy' and respectable form of femininity.

If alcohol consumption can be defined as something that is conducive to 'doing' both female friendships and femininities, this offers opportunities for women to reframe a more masculine pastime in different ways. The 'girling' of particular drinking choices and practices may help to rupture the linkages between public drinking and masculinity and recast women's presence and alcohol consumption in the contemporary NTE as feminine and respectable. This is likely to be an important practice for young women who - in contrast to their male peers - have until relatively recently experienced restrictions in terms of how and with whom they can drink in public (Day et al. 2004). Although - as I have discussed elsewhere - the women did also talk about getting drunk as a pleasure in its own right (Nicholls 2019), this focus on the perceived benefits of alcohol in terms of enhanced sociability, intimacy and trust allows women to frame drinking as something that has wider benefits than simply providing a means to get 'wasted' (a practice framed as traditionally unfeminine). Rather, drinking together was more typically framed as 'a pleasurable and socially embodied friendship practice' (Niland et al. 2013: 530), an intimate experience (Waitt and De Jong 2014) and a way to embody 'girliness'. This is borne out elsewhere, with Hunt et al. (2010) suggesting it is easier 
for men to talk about the pleasures of drinking and getting drunk as an end in itself, whilst women are required to draw on the wider social and emotional effects of drinking as justification for consumption.

The findings outlined here clearly have implications for non-drinkers and for young women who wish to moderate their alcohol consumption. A perceived refusal to 'buy into' drinking cultures may have very real consequences for women regardless of class background or sexuality, including peer pressure, interrogation and social exclusion. Whilst the original research did not specifically seek to investigate the experiences of young women who abstain from consuming alcohol, clearly some interesting findings around non-drinking and abstinence have started to emerge here. Research into the experiences of non-drinkers remains limited in comparison to research with those who drink; these emerging themes should be explored further through research attending to the experiences of non-drinkers, particularly former drinkers who decide to stop drinking for 'culturally unsanctioned' reasons (Conroy and de Visser 2014). Increasing research with young non-drinkers may also help to raise the profile of this growing group (Duncan and Levett 2017), normalise the choice to abstain from alcohol and bring this lifestyle choice to public attention. With Millennials touted as the 'sober generation' (Pape et al. 2018) and drinking continuing to decline amongst young people (Oldham et al. 2018), further work on non-drinkers and the ways in which they negotiate gendered identities and maintain friendships in nightlife spaces would be useful and timely.

Declarations of interests: None

Funding: This work was supported and funded by the Economic and Social Research Council under Grant 1116903.

Acknowledgments: I would like to express my ongoing gratitude to Professor Diane Richardson and Professor Janice McLaughlin for their guidance and support throughout all stages of this project. Thank you also to the young women who so kindly gave up their time to share their experiences and reflections with me. 


\section{References}

Advocat, J. and Lindsay, J. (2015). To drink or not to drink? Young Australians negotiating the social imperative to drink to intoxication. Journal of Sociology, 51(2), 139-153.

Atkinson, A.M., Kirton, A.W. and Sumnall, H.R. (2012). The gendering of alcohol in consumer magazines: An analysis of male and female targeted publications. Journal of Gender Studies, 21(4), 365-386.

Bailey, L., Griffin, C. and Shankar, A. (2015). "Not a good look”: Impossible dilemmas for young women negotiating the culture of intoxication in the United Kingdom. Substance Use \& Misuse, 50, 747-758.

Bancroft, A., Zimpfer, M.J., Murray, O. and Karels, M. (2014). Working at pleasure in young women's alcohol consumption: A participatory visual ethnography. Sociological Research Online, 19(3), 1-14.

Banister, E., Piacentini, M., \& Grimes, A. (2015). Identity refusal and the non-drinking self. Advances in Consumer Research, 43, Association for Consumer Research, 457-458.

Barton, A. and Husk, K. (2014). "I don't really like the pub [...]": Reflections on young people and preloading alcohol. Drugs and Alcohol Today, 14(2), 58-66.

Bartram, A., Eliott, J., and Crabb, S. (2017). 'Why can't I just not drink?' A qualitative study of adults' social experiences of stopping or reducing alcohol consumption. Drug and Alcohol Review, 36(4), 449-455

Braun, V., and Clarke, V. (2006). Using thematic analysis in psychology. Qualitative Research in Psychology, 3, 77-101. 
Brown, R. (2014). A Girls' Night Out: Gender, Subjectivity and Pleasure. PhD thesis. University of Sydney.

Butler, J. (2004). Undoing gender. London: Routledge.

Chatterton, P. and Hollands, R. (2003). Urban nightscapes : Youth cultures, pleasure spaces and corporate power. London: Routledge.

Conroy, D., and de Visser, R.O. (2013). 'Man up!': Discursive constructions of non-drinkers among UK undergraduates. Journal of health psychology, 18(11), 1432-1444.

Conroy, D., and de Visser, R.O. (2014). Being a non-drinking student: An interpretative phenomenological analysis. Psychology \& Health, 29(5), 536-551.

Conroy, D., and de Visser, R.O. (2015). The importance of authenticity for student non-drinkers: An interpretative phenomenological analysis. Journal of Health Psychology, 20(11), pp. 1483-1493.

Curtin, N., Ward, L.M., Merriwether, A. and Caruthers, A. (2011). Femininity ideology and sexual health in young women: A focus on sexual knowledge, embodiment, and agency. International Journal of Sexual Health, 23(1), 48-62.

Day, K., Gough, B. and McFadden, M. (2004). "WARNING! ALCOHOL CAN SERIOUSLY DAMAGE YOUR FEMININE HEALTH": A discourse analysis of recent British newspaper coverage of women and drinking. Feminist Media Studies, 4(2), 165-183.

Dietler, M. (2006). Alcohol: Anthropological/archaeological perspectives. Annual Review of Anthropology, 35, 229-249. 
Drinkaware (no date). Consumption: Adult drinking in the UK. Retrieved 10/01/2019 from

https://www.drinkaware.co.uk/research/data/consumption-

uk/\#Breakdown\%20of\%20alcohol\%20risk\%20levels.

Duncan, P. and Levett, C. (2017). More than a quarter of young adults in the UK do not drink alcohol - in data. The Guardian. Retrieved 10/01/2019 from

https://www.theguardian.com/society/datablog/2017/may/06/more-than-a-quarter-of-young-adults-inthe-uk-do-not-drink-alcohol-in-data.

Emslie, C., Hunt, K. and Lyons, A. (2015). Transformation and time-out: The role of alcohol in identity construction among Scottish women in early midlife. International Journal of Drug Policy, 26(5), 437445.

Emslie, C., Lennox, J., and Ireland, L. (2017). The role of alcohol in identity construction among LGBT people: A qualitative study. Sociology of Health and IIIness, 39(8), 1465-1479.

Fileborn, B. (2016). Reclaiming the Night-Time Economy: Unwanted sexual attention in pubs and clubs. London: Palgrave Macmillan.

Furtwængler, N.A and de Visser, R.O. (2013). Lack of international consensus in low-risk drinking guidelines. Drug and Alcohol Review, 32(1), 11-18.

Green, E. (1998). 'Women doing friendship': An analysis of women's leisure as a site of identity construction, empowerment and resistance. Leisure Studies, 17(3), 171-185.

Griffin, C., Bengry-Howell, A., Hackley, C., Mistral, W. and Szmigin, I. (2009a). The allure of belonging: young people's drinking practices and collective identification. In M. Wetherell (Ed.) Identity in the 21st century: New trends in new times (pp. 213-230). London: Palgrave. 
Griffin, C., Bengry-Howell, A., Hackley, C., Mistral, W. and Szmigin, I. (2009b). 'Every time I do it I annihilate myself': loss of (self-)consciousness and loss of memory in young people's drinking narratives. Sociology, 43(3), 457-476.

Griffin, C., Szmigin, I., Bengry-Howell, A., Hackley, C. and Mistral, W. (2013). Inhabiting the contradictions: hypersexual femininity and the culture of intoxication among young women in the UK. Feminism \& Psychology, 23, 184-206.

Guise, J.M.F. and Gill, J.S. (2007). 'Binge drinking? It's good, it's harmless fun': A discourse analysis of accounts of female undergraduate drinking in Scotland. Health Education Research, 22(6), 895906.

Hartley, J.E.K., Wight, D. and Hunt, K. (2014). Presuming the influence of the media: Teenagers' constructions of gender identity through sexual/romantic relationships and alcohol consumption. Sociology of Health \& IIIness, 36(5), 772-786.

Haydock, W. (2009). Gender, Class and 'Binge' Drinking: An Ethnography of Drinkers in Bournemouth's Night-Time Economy. PhD thesis. Bournemouth University.

Hayward, K. and Hobbs, D. (2007). Beyond the binge in 'Booze Britain': Market-led liminalization and the spectacle of binge drinking. The British Journal of Sociology, 58(3), 437-456.

Herman-Kinney, N.J., and Kinney, D.A. (2013). Sober as deviant: The stigma of sobriety and how some college students "stay dry" on a "wet" campus. Journal of Contemporary Ethnography, 42(1), 64-103.

Herridge, K.L., Shaw, S.M. and Mannell, R.C. (2003). An exploration of women's leisure within heterosexual romantic relationships. Journal of Leisure Research, 35(3), 274-291. 
Herring, R., Bayley, M., and Hurcombe, R. (2014). "But no one told me it's okay to not drink": a qualitative study of young people who drink little or no alcohol. Journal of Substance Use, 19(1-2), 95102.

Holland, J., Ramazanoglu, C., Sharpe, S. and Thomson, R. (2004). The male in the head: Young people, heterosexuality and power. 2nd edn. London: Tufnell.

Holland, S. (2004). Alternative femininities: Body, age and identity. Oxford: Berg.

Hunt, G., Moloney, M., and Evans, K. (2010). Youth, drugs, and nightlife. London: Routledge.

Järvinen, M., and Gundelach, P. (2007). Teenage drinking, symbolic capital and distinction. Journal of Youth Studies, 10(1), 55-71.

Jayne, M., Valentine, G. and Holloway, S.L. (2010). Emotional, embodied and affective geographies of alcohol, drinking and drunkenness. Transactions of the Institute of British Geographers, 35(4), 540554.

Jayne, M., Valentine, G. and Holloway, S.L. (2011). Alcohol, drinking and drunkenness: (Dis)orderly spaces. Farnham: Ashgate.

Joffe, H. (2012). Thematic analysis. In D. Harper and A.Thompson (Eds.) Qualitative research methods in mental health and psychotherapy: A guide for students and practitioners (pp. 210-223). Chichester: Wiley-Blackwell.

Kovac, L.D. and Trussell, D.E. (2015). 'Classy and never trashy': Young women's experiences of nightclubs and the construction of gender and sexuality. Leisure Sciences, 37, 195-209.

Letherby, G. (2002). Claims and disclaimers: Knowledge, reflexivity and representation in feminist research'. Sociological Research Online, 6, 4. 
Leve, M., Rubin, L. and Pusic, A. (2011). Cosmetic surgery and neoliberalisms: Managing risk and responsibility. Feminism \& Psychology, 22(1), 122-141.

Lyons, A.C. and Willott, S.A. (2008). Alcohol consumption, gender identities and women's changing social positions. Sex Roles, 59(9-10), 694-712.

MacLean, S. (2016). Alcohol and the constitution of friendship for young adults. Sociology, 50(1), 93108.

Maynard, M. (1994). Methods, Practice and Epistemology: The Debate About Feminism and Research. In M. Maynard and J. Purvis (Eds.) Researching Women's Lives from a Feminist Perspective (pp. 10-26). London: Taylor \& Francis.

McCormack, C. (2004). Storying stories: A narrative approach to in-depth interview conversations. International Journal of Social Research Methodology. 7(3), 219-236.

Measham, F. (2002). "Doing gender" - "doing drugs": Conceptualizing the gendering of drugs cultures. Contemporary Drug Problems. 29(1), 335 - 373.

Nairn, K., Higgins, J., Thompson, B., Anderson, M. and Fu, N. (2006). 'It's just like the teenage stereotype, you go out and drink and stuff': hearing from young people who don't drink. Journal of Youth Studies, (9)3, 287-304.

Nicholls, E. (2017). 'Dulling it down a bit': managing visibility, sexualities and risk in the Night Time Economy in Newcastle, UK. Gender, Place \& Culture, 24(2), 260-273.

Nicholls, E. (2019) Negotiating Femininities in the Neoliberal Night-Time Economy: Too Much of a Girl? London: Palgrave Macmillan. 
Niland, P., Lyons, A.C., Goodwin, I. and Hutton, F. (2013). "Everyone can loosen up and get a bit of a buzz on": Young adults, alcohol and friendship practices. International Journal of Drug Policy, 24(6), 530-537.

Oldham, M., Holmes, J., Whitaker, V., Fairbrother, H., \& Curtis, P. (2018). Youth drinking in decline. Report. University of Sheffield, Sheffield.

Papagaroufali, E. (1992). Uses of alcohol among women: Games of resistance, power and pleasure. In D. Gefou-Madianou (Ed.) Alcohol, gender and culture (pp. 48-69). London: Routledge.

Pape, H., Rossow, I., and Brunborg, G.S. (2018). Adolescents drink less: How, who and why? A review of the recent research literature. Drug and Alcohol Review, 37, 98-114.

Peralta, R.L. (2008). "Alcohol allows you to not be yourself": Toward a structured understanding of alcohol use and gender difference among gay, lesbian, and heterosexual youth. Journal of Drug Issues, 38(2), 373-399.

Rolfe, A., Orford, J. and Dalton, S. (2009). 'Women, alcohol and femininity: A discourse analysis of women heavy drinkers' accounts. Journal of Health Psychology, 14(2), 326-335.

Romo, L.K., Dinsmore, D.R., \& Watterson, T.C. (2016). “Coming out” as an alcoholic: how former problem drinkers negotiate disclosure of their nondrinking identity. Health Communication, 31(3), 336345.

Sheehan, M. and Ridge, D. (2001). 'You become really close ... you talk about the silly things you did, and we laugh': The role of binge drinking in female secondary students' lives. Substance Use and Misuse, 36(3), 347-372.

Skeggs, B. (1997). Formations of class and gender: Becoming respectable. London: SAGE. 
Smith, O. (2014). Contemporary adulthood and the Night-Time Economy. London: Palgrave Macmillan.

Waitt, G. and Clement, S. (2016). Women drinking alcohol: Assembling a perspective from a Victorian country town, Australia. Gender, Place \& Culture, 23(8), 1121-1134.

Waitt, G. and De Jong, A. (2014). Embodied geographies of alcohol and the weekend in the Bega Valley, New South Wales, Australia. Leisure Studies, 33(2), 116-132.

Waitt, G., Jessop, L. and Gorman-Murray, A. (2011). 'The guys in there just expect to be laid': Embodied and gendered socio-spatial practices of a 'night out' in Wollongong, Australia. Gender, Place \& Culture, 18(2), 255-275.

West, C. and Zimmerman, D., H. (1987). Doing gender. Gender \& Society, 1, 125-151.

Wilkinson, S. (2017). Drinking in the dark: shedding light on young people's alcohol consumption experiences. Social \& Cultural Geography, 18(6), 739-757.

Winlow, S. and Hall, S. (2009). Living for the weekend: Youth identities in Northeast England. Ethnography, 10(1), pp. 91-113. 